\title{
UTILIZAÇÃO DE LEVANTAMENTO FLORÍSTICO COMO FERRAMENTA PARA EDUCAÇÃO AMBIENTAL
}

Autor principal:

Flavia Pacheco Alves de Souza

Orientadora:

Audrey Marques Silva Paiva

Nome da Instituição:

Instituto de Educação, Ciência e Tecnologia de São Paulo

Instituição de Fomento:

Instituto de Educação, Ciência e Tecnologia de São Paulo

E-mail de contato:

flavia_pacheco@yahoo.com.br

Palavras-chave:

árvore. bosque. produção de material didático

\section{INTRODUÇÃO}

O Instituto Federal de Educação, Ciência e Tecnologia de São Paulo (IFSP) possui uma área total de $57.450 \mathrm{~m}^{2}$ e localiza-se na Rua Pedro Vicente, 625, Bairro do Canindé, São Paulo, desde a década de 70. 


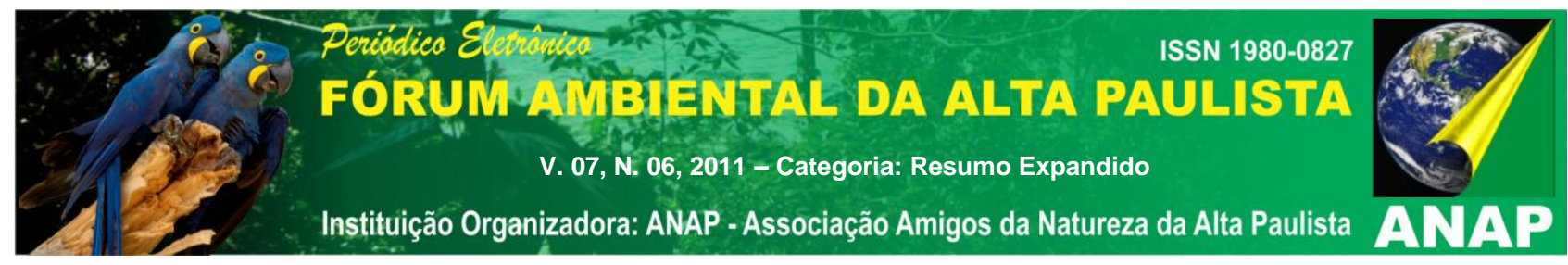

A história do Instituto remete ao ano de 1909, pelo Decreto ํo 7.566 que instituiu na capital paulista a Escola de Aprendizes e Artífices, mais tarde denominada Escola Técnica Federal de São Paulo, (1965), Centro Federal de Educação Tecnológica de São Paulo (1999) e Instituto Federal de Educação, Ciência e Tecnologia de São Paulo (2008), vinculado ao Ministério da Educação.

Ao longo da história do IFSP não houve nenhum trabalho acadêmico produzido relacionado ao levantamento de sua flora.

O bosque do campus apresenta um excelente potencial para que sejam implantadas atividades de Educação Ambiental e funcione como um "laboratório vivo" para o Ensino de Botânica na Instituição, visto que apresenta cerca de $3.894 \mathrm{~m}^{2}$ de área, com espécies arbóreas, arbustivas, herbáceas e trepadeiras.

A educação escolar a partir do Ensino Fundamental deve utilizar a educação ambiental como ferramenta pedagógica já que esta se encontra incluída nos Parâmetros Curriculares Nacionais (PCN's), no tema transversal "Meio ambiente". Sabe-se que os PCN's são um instrumento útil de apoio às discussões pedagógicas e à elaboração de projetos didáticos; porém nota-se que a educação ambiental não é inclusa no currículo escolar devido a muitos professores não entenderem sua transversalidade em sala de aula e confundi-la com o conteúdo da Ecologia.

É importante ressaltar que a educação ambiental deve ser utilizada de forma interdisciplinar, inclusive com conhecimentos de Ecologia (DIAS, 1994), enquanto Ecologia é uma ciência que tem seus próprios princípios e conceitos (RICKLEFS, 2007).

A partir desse pressuposto, propõe-se realizar o levantamento quantitativo dos indivíduos arbóreos presentes no bosque do Campus do Instituto para que este material forneça subsídios à projetos interdisciplinares de Educação ambiental no campus com estudantes de Ensino Médio, Técnico e Superior da Instituição.

Um levantamento florístico consiste em listar todas as espécies vegetais existentes em uma determinada área e, além de proporcionar conhecimento sobre as espécies botânicas de maior ocorrência, pode ser utilizado como uma ferramenta na 


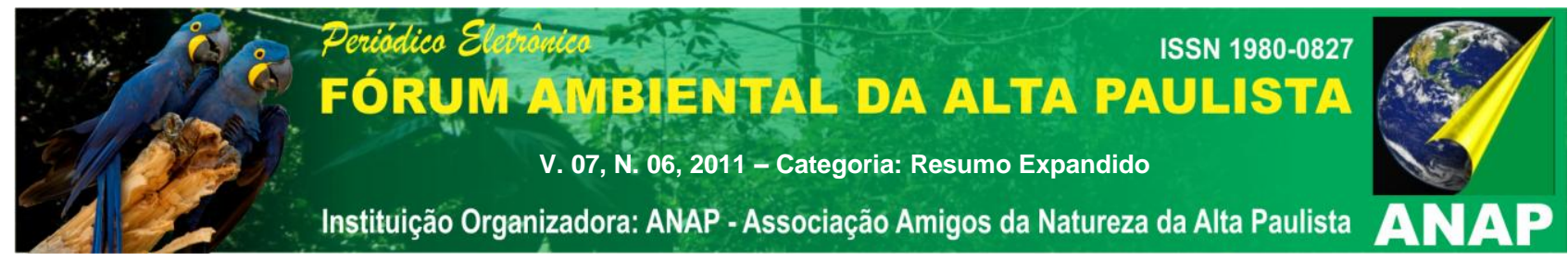

educação ambiental de forma a sensibilizar quanto às particularidades de cada espécie arbórea.

\section{OBJETIVO GERAL}

- Realizar o levantamento arbóreo das espécies existentes no bosque do campus do IFSP, gerando subsídios para o desenvolvimento de futuros projetos de pesquisa, ensino e extensão.

\section{OBJETIVOS ESPECÍFICOS}

- Produzir exsicatas do material botânico coletado no campus a serem utilizadas para fins didáticos e/ou acadêmicos;

- Georreferenciar as espécies identificadas para a confecção de mídia utilizada para fins acadêmicos e/ou didáticos;

- Identificar as árvores no campus através de emplacamento, fornecendo subsídios para atividades interdisciplinares de educação ambiental com alunos da Instituição.

\section{METODOLOGIA}

O presente trabalho teve início em abril de 2011 com duração prevista até dezembro do mesmo ano.

Para o levantamento florístico das espécies arbóreas foram realizadas três coletas semanais das espécies pertencentes ao clado das espermatófitas (gimnospermas e angiospermas).

O material botânico coletado foi herborizado em quadriplicatas, sendo uma para identificação por especialistas, uma destinada a fins didáticos, uma para coleção particular do IFSP, e uma para compor o acervo do Herbário SPF da Universidade de São Paulo - USP. 


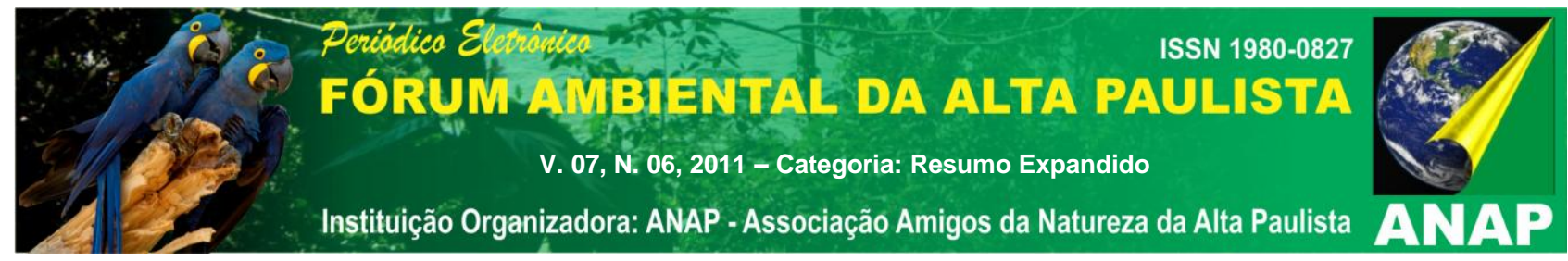

Para os indivíduos em estágio vegetativo foram coletados apenas galhos e folhas; posteriormente serão coletadas amostras do estágio reprodutivo quando este ocorrer.

Em caderno de campo foram registradas medidas diretas como o DAP (diâmetro a altura do peito) e CAP (circunferência a altura do peito); e medida indireta, como a altura dos indivíduos.

Incluiu-se também no caderno de campo as características dos exemplares como: formato do tronco, das folhas, coloração dos frutos, flores, etc., a fim de facilitar o trabalho de identificação.

Os exemplares arbóreos em período fértil foram fotografados com câmera digital, para que as imagens obtidas ao final do projeto possam subsidiar a elaboração de uma mídia ilustrada para fins didáticos e/ou acadêmicos.

\section{RESULTADOS E DISCUSSÕES}

O bosque do Campus do IFSP apresenta 406 exemplares arbóreos, sendo que destes 363 já foram identificados em suas respectivas famílias e gêneros botânicos.

Os indivíduos identificados estão distribuídos em 27 gêneros e 17 famílias (Tabela 1), notando-se predominância de MYRTACEAE (53,1\%), representada por 04 gêneros: Eucalyptus sp., Psidium sp., Sygydium sp. e Eugenia sp.; seguida por BIGNONIACEAE (11,8\%), representada por 04 gêneros: Spathodea sp., Tabebuia sp., Tecoma sp e Jacaranda sp.; e FABACEAE (8,5\%), também representada por 04 gêneros: Bauhinia sp., Delonix sp., Caesalpinia sp. e Tipuana sp.

Tabela 1. Indivíduos arbóreos do IFSP distribuídos em famílias

\begin{tabular}{llll}
\hline Família & $\begin{array}{l}\text { Quantidade } \\
\text { de gêneros }\end{array}$ & $\begin{array}{l}\text { Quantidade de } \\
\text { indivíduos }\end{array}$ & $\begin{array}{l}\text { Porcentagem } \\
(\%)\end{array}$ \\
\hline MYRTACEAE & 04 & 193 & 53,1 \\
BIGNONIACEAE & 04 & 043 & 11,8
\end{tabular}




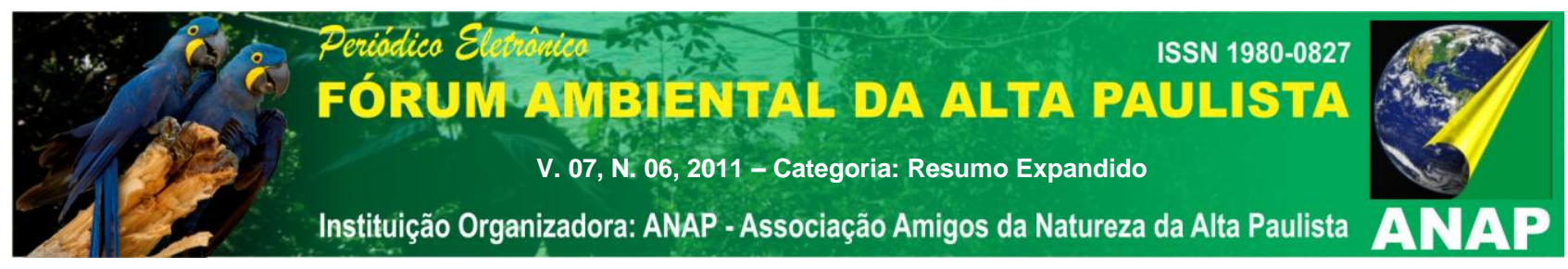

\begin{tabular}{llll} 
FABACEAE & 04 & 031 & 8,5 \\
OLEACEAE & 01 & 017 & 4,7 \\
RHAMNACEAE & 01 & 017 & 4,7 \\
ANACARDIACEAE & 01 & 015 & 4,1 \\
ARECACEAE & 01 & 012 & 3,3 \\
(PALMAE) & & & \\
MELIACEAE & 01 & 011 & 3,0 \\
LITHRACEAE & 01 & 006 & 1,7 \\
MALVACEAE & 01 & 004 & 1,1 \\
MORACEAE & 02 & 003 & 0,8 \\
PINACEAE & 01 & 003 & 0,8 \\
POLYGONACEAE & 01 & 003 & 0,8 \\
ROSACEAE & 01 & 002 & 0,5 \\
APOCYNACEAE & 01 & 002 & 0,5 \\
URTICACEAE & 01 & 001 & 0,3 \\
MELASTOMACEAE & 01 & 001 & 0,3 \\
\hline
\end{tabular}

SOUZA, F.P.A. , 2011

Dentre os exemplares identificados, $83 \%$ são espécies exóticas; isto é, oriundas de outros Países e 17\% são espécies nativas. Tal fato é sustentado pela vegetação do campus ser totalmente introduzida entre as décadas de 70 a 80 , em que se contemplavam espécies exóticas arbóreas no Paisagismo urbano, fato que pode ser amplamente discutido em termos ecológicos e ambientais com os alunos.

As exsicatas produzidas já estão disponíveis para utilização em Disciplinas de Botânica no IFSP; sendo que na semana de Tecnologia que ocorrerá em outubro de 2011 será ministrado um curso que tem por objetivo apresentar estratégias para o ensino de Botânica na Educação Básica, utilizando exsicatas e atividades monitoradas de Educação Ambiental no campus utilizando a diversidade arbórea. 


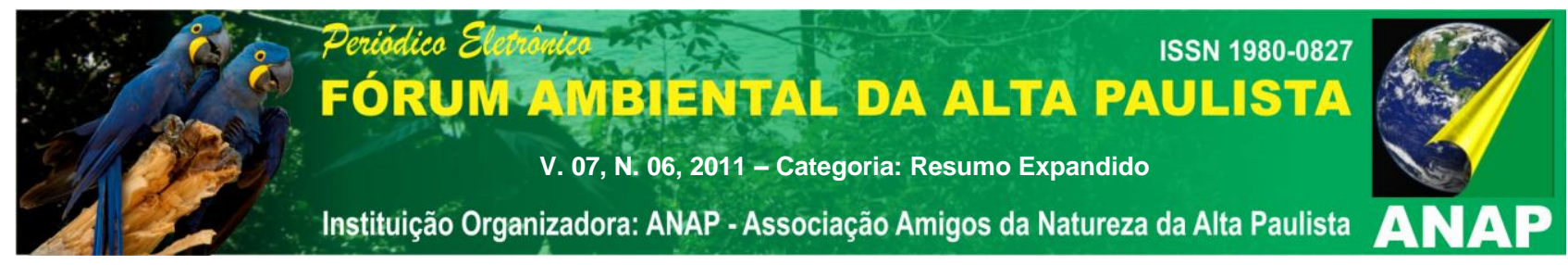

\section{CONSIDERAÇÕES FINAIS}

Com o seguinte trabalho foi possível realizar o levantamento quantitativo do Bosque do IFSP quanto à vegetação arbórea, podendo-se perceber que a maioria das árvores existentes são espécies exóticas. As árvores do Campus estão distribuídas em 17 famílias botânicas e 27 gêneros.

Quanto ao georreferenciamento das espécies e o emplacamento das árvores previsto nos objetivos, estas etapas serão concluídas até o término do projeto, em dezembro de 2011.

Pretende-se desenvolver atividades práticas no bosque do Campus que possam contribuir de forma ampla e completa para que estudantes possam compreender as teorias expostas nas aulas de Botânica, bem como se sensibilizar pelo ambiente e biodiversidade.

\section{REFERÊNCIAS}

DIAS, G.F. Atividades interdisciplinares de educação ambiental. São Paulo: Global, 1994.

FIDALGO, O.; BONONI, V. L. R. Técnica de coleta, preservação e herborização de material botânico. São Paulo: Instituto de Botânica, 1984. 62p. Manual oo 04.

LORENZI, Harri. Árvores brasileiras - Manual de identificação e cultivos de plantas arbóreas nativas do Brasil. 4ed. Nova Odessa-SP: Instituto Plantarum, 2002. 384p. v. 1. LORENZI, Harri. Árvores brasileiras - Manual de identificação e cultivos de plantas arbóreas nativas do Brasil. 2ed. Nova Odessa-SP: Instituto Plantarum, 2002. v.2 386p.

LORENZI, Harri; et al. Árvores exóticas no Brasil - madeireiras, ornamentais e aromáticas. Nova Odessa-SP: Instituto Plantarum, 2003. 368p.

SOUZA, V.C.; LORENZI, H. Botânica sistemática. 2ed. Nova Odessa-SP: Instituto Plantarum, 2008. 704p.

ODUM, E.P. Fundamentos de ecologia. 5ed. São Paulo: Thomson Pioneira, 2007. 612p. 
RAVEN, Peter H.; EVERT, Ray F.; EICHHORN, Susan E. Biologia Vegetal. Rio de Janeiro: Guanabara Books, 2007.

RICKLEFS, Robert E. A economia da natureza. 5ed. Rio de Janeiro: Guanabara Koogan, 2007. 